\section{Filling Ability and Flow of Root Canal Sealers: A Micro- Computed Tomographic Study}

Jáder Camilo Pinto ${ }^{10}$, Fernanda Ferrari Esteves Torres ${ }^{10}$, Mariana Mena Barreto Pivoto-João ${ }^{10}$, Joni Augusto Cirelli2 $\mathbb{E}^{-}$, Juliane Maria GuerreiroTanomaru $^{10}$, Mário Tanomaru-Filho ${ }^{1}$ (])
'Department of Restorative Dentistry, School of Dentistry, UNESP - Universidade Estadual Paulista, Araraquara, SP, Brazil 2Department of Diagnosis and Surgery, School of Dentistry, UNESP - Universidade Estadual Paulista, Araraquara, SP, Brazil

Correspondence: Dr. Mario Tanomaru-Filho, Rua Humaitá, 1680, 14801-903 Araraquara, SP, Brasil. Tel: +55-16-3301-6390. e-mail: tanomaru@uol.com.br
This study evaluated by micro-computed tomography $(\mu \mathrm{CT})$ the filling ability in curved root canals, besides the flow of AH Plus (AHP) and Neo MTA Plus (NMTAP) sealers using different methodologies. Mandibular molars mesial roots with two root canals and degree of curvature between $20^{\circ}$ and $40^{\circ}$ were selected. The specimens were prepared with the ProDesign R system up to size 35.05 and were filled with the sealers by a continuous wave of condensation technique, Thermo Pack II $(n=12)$. The teeth were scanned using $\mu \mathrm{CT}$ after root canal preparation and obturation. The volumetric percentage of filling material and voids were calculated. Flow was evaluated based on ISO 6876/2012 ( $n=10)$. Flow and filling were also evaluated in $\mu \mathrm{CT}$ using a glass plate with a central cavity and four grooves from the central cavity $(n=6)$. Flow was linearly calculated into the grooves. The central cavity filling (CCF) and lateral cavity filling (LCF) were calculated in $\mathrm{mm}^{3}$. Data were submitted to non-paired t test with a significance threshold at $5 \%$. The percentage of filling and voids between the root canals filled with AHP or NMTAP was similar ( $p>0.05)$. NMTAP presented the lowest flow in conventional test $(p<0.05)$. Using $\mu C T$, sealers had similar CCF, LCF and linear flow ( $p>0.05$ ). In conclusion, NMTAP and AHP had similar filling ability in curved mesial root canals of mandibular molars without presence of isthmus. Although AHP presented better flow than NMTAP using ISO methodology, there was no difference between these materials regarding volumetric filling when evaluated by $\mu \mathrm{CT}$.
Key Words: endodontics, physical properties, root canal obturation, $\mathrm{x}$-ray microtomography.

\section{Introduction}

Three-dimensional root canal obturation should promote a consistent filling of the canal space to prevent re-infection (1). Compaction of heated gutta-percha is advantageous, since it decreases the sealer thickness and increases the volume of gutta-percha (2), and guttapercha is a stable material (3). The continuous wave of condensation technique promotes vertical compaction of gutta-percha in the apical third, followed by injection of heated gutta-percha for root canal filling (4). However, obturation techniques require endodontic sealers for filling spaces between the gutta-percha and root canal wall (5) or even the irregularities and areas that are difficult to access (4).

AH Plus sealer (AHP) (Dentsply DeTrey GmbH, Konstanz, Germany) is an epoxy resin-based material considered the gold-standard due to its excellent physicochemical properties (6). Recently, calcium silicate-based endodontic materials have been proposed since they are biocompatible and bioactive (7). Neo MTA Plus (NMTAP) (Avalon Biomedic Inc. Bradenton, $\mathrm{FL}, \mathrm{USA}$ ) is a tricalcium silicate-based sealer with small particles, which allows penetration into the dentinal tubules (8). However, no study was performed to evaluate the flow or the filling ability of NMTAP sealer by means of micro-computed tomography $(\mu \mathrm{CT})$.

Curved root canals can be challenging in the preparation of the root canal (9). The literature on the filling of curved canals is limited (2), and there is no study comparing different sealers in this anatomy. $\mu \mathrm{CT}$ is a method used for comparison between the filling of different techniques and filling materials (10-12). The root canals may be evaluated quantitatively and qualitatively (10).

Among the important physicochemical properties for root canals filling, it is expected that flow of endodontic sealers allow penetration into the root canal irregularities, isthmus and ramifications (13). However, the flow of endodontic materials evaluated by conventional methods does not necessarily is correlated with their filling ability (14). A previous study proposed a device using $\mu \mathrm{CT}$ to evaluate flow and filling ability of root-end filling materials (14). The device designed with two glass plates allows standardization of the amount of material and pressure on the material during the test, similarly to that proposed by the ISO standards. Moreover, grooves in the bottom glass plate allow the concomitant evaluation of flow and filling abilities. Thus, this new technique is promising for answering two material properties simultaneously, and there is no study assessing root canal sealers by this method yet. 
The aim of this study was to evaluate the percentage of filling and voids using curved mesial canals of mandibular molars filled with AHP and NMTAP by continuous wave of condensation, besides the flow values of these root canal sealers using conventional ISO methodology in comparison with a technique using $\mu \mathrm{CT}$ to assess their flow and filling abilities. The null hypotheses were that there would be no significant difference in the percentage of voids using AHP or NMTAP and no difference between the flow and filling properties.

\section{Material and Methods}

The materials used, their manufacturers and proportion are represented in Table 1.

\section{Filling Ability in Root Canals Evaluated By $\mu \mathrm{CT}$ Specimen Selection}

According to a previous study with similar methodology (11), the sample size for this study was calculated with a specific software $\left(G{ }^{*}\right.$ Power 3.1.7 for Windows, Heinrich Heine, Universitat Dusseldorf). The t-test for two independent groups was used, with alpha type error of .05, beta power of .95 and effect size of 1.73. Nine specimens $\therefore$ per group were indicated as the ideal size required. A sample of 12 root canals per group was used.

After approval by the Ethics Committee (CEP no. 98683818.0.0000.5416), human mandibular molars with two separated mesial root canals were selected by a digital radiography system Kodak (RVG 6100; Kodak Dental Systems, NY, USA) and $\mu$ CT (SkyScan 1176; Bruker, Kontich, Belgium). Scanning was performed with a voxel size of 35 $\mu \mathrm{m}$, with the following parameters: copper and aluminum filter, exposure time of $87 \mathrm{~ms}$, frame averaging 3, rotation $180^{\circ}$, rotation step $0.5,80 \mathrm{kV}$ and $300 \mathrm{uA}$.

The mesial roots presented type IV configuration according to the classification of Vertucci (15). Complete apical formation, absence of root fractures, angle of curvature between $20^{\circ}$ and $40^{\circ}$ and radius of curvature smaller than $10 \mathrm{~mm}$, were observed in accordance with Schneider method (16). The size of the teeth was standardized at $18 \mathrm{~mm}$ with a tolerance of $\pm 2 \mathrm{~mm}$ of discrepancy. A total of twelve roots were selected, totalizing twenty-four root canals, including mesiobuccal and mesiolingual canal of each root. The samples were stored in a $0.1 \%$ Thymol solution at $5{ }^{\circ} \mathrm{C}$.

\section{Root Canal Preparation}

The access to the canals was obtained with a bur (n.2, KG Sorensen, São Paulo, Brazil) and the root canals were explored using K \# 10 files (Dentsply Maillefer, Ballaigues, Switzerland) up to the apical foramen. The working length was established $1 \mathrm{~mm}$ short of the apical foramen, and patency was established at this length, both mesiobuccal and mesiolingual canals. The roots were embedded in condensation silicone (Oranwash, Zhermack SpA, Badia Polesine, Italy) to simulate the periodontal ligament. After this, a single, experienced operator performed the root canal preparations.

The ProDesign R (Easy Dental Equipments, Belo Horizonte, MG, Brazil) instruments size 25, taper 0.06 were operated by an electric motor VDW SILVER (VDW GmbH, Munich, Germany) set in the "RECIPROC ALL" function, in accordance with the manufacturer's instructions. Each instrument was gradually inserted into the canal in inand-out movements, at the three levels (cervical, middle and apical) up to working length. The root canals were enlarger with ProDesign $\mathrm{R}$ size 35 , taper 0.05 as describe above. The root canal irrigation was performed with $5 \mathrm{~mL}$ of $2.5 \%$ sodium hypochlorite $(\mathrm{NaOCl})$, using a $30 \mathrm{G}$ sidevented needle (NaviTip, Ultradent Products, South Jordan, UT) adapted to a $5 \mathrm{~mL}$ syringe (Ultradent Products), which was placed $2 \mathrm{~mm}$ short of the working length. As final irrigation, $2 \mathrm{~mL}$ of $17 \%$ EDTA followed by $5 \mathrm{~mL}$ of distilled water were used as described above.

\section{Root Canal Filling}

After preparation, the root canals were divided into two experimental groups $(n=12)$, with stratified random sampling, considering the volume of prepared canals. The root canals were filled with AHP or NMTAP by the continuous wave of condensation technique - Thermo Pack II (Easy Equipamentos Odontológicos).

Gutta-percha cones size 35 taper 0.05 (Tanari industry Ltda., São Paulo, SP, Brazil) were were selected according

Table 1. Materials, their manufacturer, composition, and proportions used

\begin{tabular}{|c|c|c|}
\hline Materials & Manufacturer/ Composition & Proportion \\
\hline AH Plus & $\begin{array}{c}\text { Dentsply DeTrey GmbH,Konstanz, Germany . Epoxy resin bisphenol-A } \\
\text { and bisphenol-F, calcium tungstate, zirconium oxide, silica, iron } \\
\text { pigments. Dibenzyl diamide, aminoadamantane, silicone oil }\end{array}$ & $\begin{array}{l}\text { Equal portions (by length) of } \\
\text { the base and catalyst paste }\end{array}$ \\
\hline Neo MTA Plus & $\begin{array}{l}\text { Avalon Biomed Inc., Bradenton, FL, USA. Powder: tricalcium } \\
\text { silicate, dicalcium silicate, tantalum oxide, tricalcium } \\
\text { aluminate, and calcium sulphate. Liquid: water-based gel } \\
\text { with thickening agent and water soluble polymers. }\end{array}$ & $\begin{array}{l}1 \text { scoop of powder to } 1 \text { drop of gel } \\
(0.33 \text { g powder to } 150 \mu \mathrm{L} \text { gel })\end{array}$ \\
\hline
\end{tabular}


to the tip size and taper measured in the profilometer (Profile Projector Nikon Model 6C-2). After radiographic evaluation of adaptation of the gutta-percha cone selected, the sealer was placed into the root canal by using a Lentulo 35 instrument (Dentsply Maillefer) and manual K-file 35 pre-curved (Dentsply Maillefer). After this, the gutta-percha cone covered by endodontic sealer was placed in the root canal. The thermoplastic plugger from the Termo Pack II System (Easy Dental Equipments) was used for plasticization, cutting and compaction of the gutta-percha within the apical root canal up to $3 \mathrm{~mm}$ of the working length. After this, the thermal injector of the system was used to inject the warmed gutta-percha that was compacted. Compaction was performed with NiTi condensers (Easy Dental Equipments). A radiograph was taken to verify radiographic the quality of the obturation.

After filling the root canals, each sample was sealed with provisional Coltosol (Vigodent, Rio de Janeiro, RJ, Brazil) restorative material, and kept in an oven at a temperature of $37^{\circ} \mathrm{C}$, in $95 \%$ humidity, for 3 days.

\section{$\mu C T$ Analysis}

The roots were scanned using $\mu \mathrm{CT}$ (SkyScan 1176; Bruker $\mu \mathrm{CT}$, Kontich, Belgium) after preparation, and after the obturation of the root canals. The roots were positioned in a standardization device, allowing the specimens to remain in the same position at all times during scanning procedures. The parameters used were: $90 \mathrm{kV}$ of power, energy of $278 \mathrm{~mA}$, evolution cycle of $180^{\circ}$, rotation of 0.5 , $\mathrm{Cu}+\mathrm{Al}$ filter and voxel size of $9 \mu \mathrm{m}$. The post-preparation and post-obturation images obtained were reconstructed using the NRecon software (NRecon v.1.6.10.4, Bruker $\mu \mathrm{CT}$ ), Volumetric analysis was performed in all canals after the preparation, through the software CTAn (CTAn v.1.14.4, Bruker $\mu \mathrm{CT}$ ) with the use of specific task lists.

The reconstructed images, obtained before and after obturation, were superimposed by means of geometric alignment in the Data Viewer software (Data Viewer v.1.5.1, Bruker $\mu \mathrm{CT}$ ). Quantitative analyses were then made using the CTAn software by applying task lists, and arithmetic and logic operations between the superimposed sections. Root canal volume, filling material volume (gutta-percha and sealer), and voids were quantified. The gray scale range required to recognize each object under study was determined in a density histogram by using a adaptative threshold method. The percentages of filling material were taken as a basis on the post-preparation volume of the canal and on the filling volume: [percentage of filling = (volume of filling $\times 100$ ) / volume of canal]. The volume of voids was calculated by subtracting the filling material volume from the post-preparation root canal volume: [volume of voids $=$ volume of canal - volume of filling] .
The percentage volume of voids was calculated by using the following formula: [Percentage of voids $=$ (volume of voids X 100)/volume of canal]. Representative images were performed by means of models obtained by using CTVol software (CTVol v. 2.0, Bruker $\mu \mathrm{CT}$ ).

Evaluation was performed at all root canal extension and by thirds (cervical, middle and apical). the value of approximately $9 \mathrm{~mm}$ was determined for the total length analysis and approximately $3 \mathrm{~mm}$ for each third. In the software (CTAn), the value of bottom was corresponding to the working length, and to this value was added $9 \mathrm{~mm}$, as the value of top, corresponding to the furcation level.

\section{Flow Test Following ISO Standard 6876}

The flow test was conducted in accordance with ISO Standard 6876/2012. After manipulation of the sealer, $0.05 \mathrm{~mL}$ of the material was placed in the center of a glass plate by using a graduated syringe $(n=10)$. At $180 \pm 5$ $s$ after initiating the manipulation, another glass plate (20 g) was placed on the plate with the sealer, and a 100-gram weight was put on the top plate and kept there for $10 \mathrm{~min}$. After this period, the maximum and minimum diameters of the material on the glass plate were measured. When a difference of less than $1 \mathrm{~mm}$ between the diameters was observed, the mean value was recorded.

\section{Flow and Filling Using $\mu C T$}

The flow test by $\mu \mathrm{CT}$ was conducted in accordance with a previous study (14). A glass plate was fabricated with a

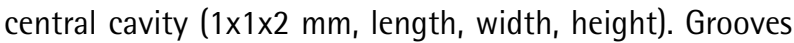
of equal size were made in the cavity, extending out 12 $\mathrm{mm}$ horizontally and vertically to the 4 sides. The amount of sealer was based on the ISO Standard 6876 flow test. An amount of $0.05 \pm 0.005 \mathrm{ml}$ of each material $(\mathrm{n}=6)$ was placed in the central cavity (Fig. 1A), and another glass $(20 \mathrm{~g})$ and metal weight $(100 \mathrm{~g}$ ) with a total mass of $120 \mathrm{~g}$ were placed on the materials (Fig. 1B) and kept there for 10 min. After completion of the initial setting time, the plate/material


Figure 1. Illustration of the amount of endodontic sealer placed in the central cavity by using a graduated syringe (A). View representing the set formed by the glass plates, sealer and metal weight (B). 3D models representing the flow and filling of AHP (C) and NMTAP (D) inside the cavities. 
set was scanned individually. Scanning was performed by $\mu \mathrm{CT}$ SkyScan 1176 and completed using $90 \mathrm{kV}$ X-ray tube voltages and a $278 \mu \mathrm{A}$ anode current; 0.1 -mm copper filter; isotropic voxel of $9 \mu \mathrm{m}$; and an evolution cycle of $360^{\circ}$. The linear flow $(\mathrm{mm})$ measurement of the material on each side of the grooves (horizontal and vertical) was analyzed. The mean of the 4 measurements was considered the linear flow for each evaluation. The filling in volume $\left(\mathrm{mm}^{3}\right)$ of the materials in the central area $(1 \times 1 \times 2 \mathrm{~mm}$, length, width, and height) was determined as the central cavity filling (CCF). The filling in volume $\left(\mathrm{mm}^{3}\right)$ of the materials in the lateral areas was determined up to $2 \mathrm{~mm}$ for each side extending out of the central cavity. The means of the 4 measurements were considered the lateral cavity filling (LCF) for each analysis. Images were reconstructed using NRecon. The correction parameters of smoothing, beam hardening and ring artifacts were defined individually for each material. The reconstructed images were saved in the coronal, sagittal and transaxial planes in the DataViewer software. The images were analyzed by using CTAn software. 3D models representing the flow and filling of each sealer inside the cavities were created in the CTVox software (CTVox v.3.2.0 Bruker $\mu \mathrm{CT}$ ) (Figs. 1C and D).

\section{Statistical Analysis}

All data were analyzed with statistical software package GraphPad Prism 7.00 (GraphPad Software Inc., La Jolla, CA, USA). The data were submitted to the Shapiro-Wilks

Table 2. Mean and standard deviation of the volume $\left(\mathrm{mm}^{3}\right)$ after, preparation expressed as total values and valued by root third

\begin{tabular}{lll}
\hline & AH Plus & Neo MTA Plus \\
\hline Total & $3.11( \pm 0.53)$ & $3.07( \pm 0.55)$ \\
Cervical third & $1.66( \pm 0.37)$ & $1.61( \pm 0.35)$ \\
Middle third & $0.99( \pm 0.27)$ & $0.98( \pm 0.16)$ \\
Apical third & $0.39( \pm 0.09)$ & $0.40( \pm 0.07)$ \\
\hline
\end{tabular}

There was no significant difference among the root canal volumes $(p>0.05)$.

Table 3. Mean and standard deviation of the voids and filling material $(\%)$ after use of continuous wave of condensation

\begin{tabular}{lccc}
\hline & & AH Plus & Neo MTA Plus \\
\hline \multirow{4}{*}{ Voids (\%) } & Total & $7.07( \pm 3.24)$ & $6.53( \pm 2.91)$ \\
& Cervical third & $7.88( \pm 3.02)$ & $6.73( \pm 3.22)$ \\
& Middle third & $9.33( \pm 2.06)$ & $7.69( \pm 2.77)$ \\
& Apical third & $7.07( \pm 3.41)$ & $7.29( \pm 2.57)$ \\
Filling & Total & $92.92( \pm 3.24)$ & $93.47( \pm 2.91)$ \\
material $(\%)$ & Cervical third & $92.12( \pm 3.02)$ & $93.27( \pm 3.32)$ \\
& Middle third & $90.66( \pm 2.06)$ & $92.33( \pm 2.77)$ \\
& Apical third & $92.93( \pm 3.41)$ & $92.70( \pm 2.57)$ \\
\hline
\end{tabular}

There was no significant difference between the sealers $(p>0.05)$. normality tests and showed normal distribution. Non-paired $t$ test was used for comparison between the materials with a significance threshold at 5\%.

\section{Results}

\section{Filling Ability in Root Canals Evaluated by $\mu \mathrm{CT}$}

The volume of the root canals prepared by the ProDesign R 35.05 system throughout the entire extension of the canal and thirds (cervical, middle and apical) was similar for the two experimental groups for evaluation of the filling sealers ( $p>0.05$ ) (Table 2). There was no significant difference in the percentage of voids and filling between the canals obturated by the continuous wave of condensation technique with AHP or NMTAP sealers ( $p>0.05$ ) (Table 3, Fig. 2).

\section{Flow Test Following ISO Standard 6876 and Using $\mu C T$}

The results of the flow and filling tests using ISO 6876 and $\mu$ CT are represented in Table 4. AHP showed a higher linear flow rate than NMTAP according to ISO 6876 standards $(p<0.05)$. When assessing in $\mu \mathrm{CT}$, the linear rates and volumetric filling in the central and lateral cavities were similar for the materials $(p>0.05)$.

\section{Discussion}

The current study assessed flow and filling of endodontic

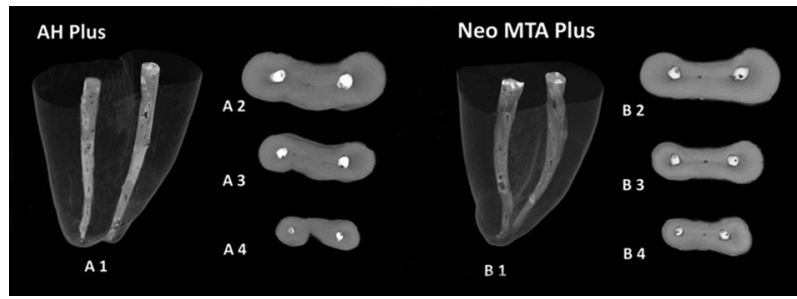

Figure 2. Three-dimensional reconstructions of images obtained by micro-CT of mesial canals of mandibular molars filled by continuous wave of condensation with AHP (A1) or NMTAP (B1). Axial sections of mesial roots of mandibular molars filled with AHP or NMTAP, respectively in the following thirds: cervical (A2, B2), middle (A3, B3) and apical (A4, B4). The filling material is represented in gray and white, and the voids can be visualized by black color.

Table 4. Mean and standard deviation of the flow $(\mathrm{mm})$ and filling $\left(\mathrm{mm}^{3}\right)$ of the sealers

\begin{tabular}{lll}
\hline & AH Plus & Neo MTA Plus \\
\hline Flow $(\mathrm{mm})-$ ISO 6876 & $21.41( \pm 1.13) \mathrm{a}$ & $13.98( \pm 1.25) \mathrm{b}$ \\
Flow $(\mathrm{mm})-\mu \mathrm{CT}$ & $8.56( \pm 0.88) \mathrm{a}$ & $7.40( \pm 0.85) \mathrm{a}$ \\
$\begin{array}{l}\text { Central cavity filling } \\
\left(\mathrm{mm}^{3}\right)-\mu \mathrm{CT}\end{array}$ & $1.76( \pm 0.20) \mathrm{a}$ & $1.95( \pm 0.09) \mathrm{a}$ \\
$\begin{array}{l}\text { Lateral cavity filling } \\
\left(\mathrm{mm}^{3}\right)-\mu \mathrm{CT}\end{array}$ & $1.47( \pm 0.13) \mathrm{a}$ & $1.63( \pm 0.15) \mathrm{a}$ \\
\hline
\end{tabular}

${ }^{a, b}$ Different letters in the same row indicate a statistically significant difference between the sealers $(\mathrm{p}<0.05)$ 
sealers by means of different methodologies. Confirming our first null hypothesis, the filling capacity in curved root canals obturated with AHP or NMTAP sealers was similar. The present study showed $92.92 \%$ as average percentage of root canal filling for AHP and 93.47\% for NMTA. A higher percentage of filling for the continuous wave of condensation technique associated with AHP sealer in mesial roots of mandibular molars than in present study was observed by Oh et al. (11), with $99.72 \%$ of filling. A lower percentage of voids (3.91\%) was also observed by Iglecias et al. (12), in comparison with our results. However, these studies were conducted by $\mu \mathrm{CT}$ at a lower scanning resolution, with voxel sizes at $17.42 \mu \mathrm{m}$ and $14.87 \mu \mathrm{m}$, respectively. In the present study, the resolution of $9 \mu \mathrm{m}$ was used for scanning, which could suggest greater capacity for detecting the presence of voids, since small features identification are directly related to the voxel size of the $\mu \mathrm{CT}$ images, and very small voids are difficult or impossible to be observed in images with low resolution (10).

Another factor that may contribute to the different percentage of filling of root canals among the studies is the different composition of gutta-percha brands used (17). Warm vertical compaction with Tanari gutta-percha cone, used in the present study, showed lower percentage of filled lateral canals than other brands, due to a lower percentage of gutta percha in its composition (17). However, Tanari is the only manufacturer that offers gutta-percha cones with taper 0.05 , with the same size of the final preparation used in the root canals (35/.05). In addition, Gurgel-Filho et al. (18) showed that Obtura and Tanari had better results than Dentsply, Konne and Analytic gutta-percha cones when it was used with the continuous wave of condensation technique.

Mesial roots of mandibular molars with a curvature between $20^{\circ}$ and $40^{\circ}$ were used in our study because the evaluation of obturation techniques in curved canals is limited (2). Preparation and obturation of root canals with anatomical complexity present greater difficulty (9). In the present study, the continuous wave of condensation technique allowed plasticization of the gutta-percha throughout the entire extension of the canal, which promotes a homogeneous mass capable of filling the irregularities of the canals (3). Therefore, the continuous wave of condensation may be considered an appropriate technique for obturation of mesial root canals of mandibular molars (19).

The effect of heating on the properties of endodontic sealers is controversial. AH Plus had changes in its chemical structure after exposure to heat (20), However, it is also considered suitable for heated root canal filling techniques (21). Regarding calcium silicate sealers, Atmeh et al. (20) stated that the application of heat had no effect on its chemical structure. Changes in epoxy resin- and zinc oxide-eugenol-based sealers were detectable at $100{ }^{\circ} \mathrm{C}$, and water loss was irreversible in calcium silicate sealers at this temperature (22). The authors do not recommend the use of temperatures above $100^{\circ} \mathrm{C}$. Regarding the filling ability of the sealers, Heran et al. (23) showed that AH Plus should not be subjected to high temperatures as its properties deteriorate and void volume increases. The two assessment methods used in the present study for material filling capacity are not directly correlated, but are complementary. However, in view of the possibility of changes in the physicochemical properties of some root canal sealants, heated techniques must be carefully considered.

When evaluating the flow of the sealers, our results showed that AHP presented high flow by the ISO standards, in agreement with a previous study (6), while NMTAP presented values below those recommended by ISO. There are no studies evaluating this property for NMTAP when used as a root canal sealer. However, the conventional ISO methodology used for evaluating the flow of root canal sealers is a linear measurement and may not reflect the filling ability of endodontic materials (14).

A previous study used $\mu \mathrm{CT}$ to evaluate the filling volume of different root canal sealers in the apical third of extracted teeth (24). These authors observed a lower volume of material for Endofill (Dentsply) and Sealapex (SybronEndo, Glendona, CA, USA), which they associated to the flow of these materials. The highest volume for AHP was related to its higher consistency. The test by $\mu \mathrm{CT}$ performed in the present study was based on Tanomaru-Filho et al. (14). This methodology is similar to that proposed by ISO considering the standardized quantity of material used and the applied pressure on the sealers. The authors used this standardized technique to analyze reparative cements flow and filling of cavities and observed that the flow ability of root-end filling materials was not compatible with the lateral volumetric filling of these cements. Therefore, $\mu \mathrm{CT}$ promotes additional information on filling ability complementing flow test by ISO.

Analysis by $\mu \mathrm{CT}$ demonstrated similar central and lateral filling for the evaluated materials. These results suggest that linear flow did not reflect the ability for filling lateral spaces. McMichael et al. (8), when evaluating the penetrability of NMTAP into dentinal tubules, observed a high percentage of penetration for this sealer. These results show proper filling of NMTAP, although this material had not shown greater flow by the conventional test. Thus, the second null hypothesis was rejected, once $\mu \mathrm{CT}$ allowed specific and different points of analysis and flow and filling ability was not completely associated.

Although the solubility of NMTAP as a root canal sealer has not been reported, high values for calcium silicate-based sealants are observed after immersion in distilled water. PBS storage reduces this solubility, but with values above 
ISO 6876 standards. Therefore, new research and greater knowledge of the behavior of these materials are important for clinical indication (25).

Within the limitations of the present study, it can be concluded that although AHP presented better flow than NMTAP using ISO methodology, there was no difference between these sealers regarding volumetric filling when evaluated by $\mu$ CT. Moreover, NMTAP showed proper filling of curved canals in association with continuous wave of condensation technique, besides adequate ability to fill central and lateral spaces, which suggest its good potential for clinical application.

\section{Resumo}

Este estudo avaliou por microtomografia computadorizada $(\mu \mathrm{CT})$ a capacidade de preenchimento de canais radiculares curvos, além do escoamento dos cimentos AH Plus (AHP) e Neo MTA Plus (NMTAP) utilizando diferentes metodologias. Foram selecionadas raizes mesiais de molares inferiores com dois canais radiculares e grau de curvatura entre $20^{\circ} \mathrm{e} 40^{\circ}$. As amostras foram preparadas com o sistema ProDesign R até o tamanho 35.05 e foram obturadas com os cimentos por uma técnica de onda continua de condensação, Thermo Pack II $(n=12)$. Os dentes foram escaneados usando $\mu$ CT após o preparo e obturação do canal radicular. A porcentagem volumétrica de material de preenchimento e vazios foram calculados. 0 escoamento foi avaliado com base na norma ISO 6876/2012 ( $n=10)$. 0 escoamento e o preenchimento também foram avaliados em $\mu$ CT usando uma placa de vidro com uma cavidade

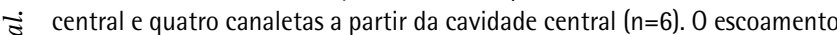
foi calculado linearmente nas canaletas. 0 preenchimento da cavidade central (PCC) e o preenchimento da cavidade lateral $(\mathrm{PCL})$ foram calculados em $\mathrm{mm}^{3}$. Os dados foram submetidos ao teste t não pareado com nivel de significância $\checkmark$ de $5 \%$. A porcentagem de preenchimento e vazios entre os canais radiculares - preenchidos com AHP ou NMTAP foi semelhante $(p>0,05)$. NMTAP apresentou o menor escoamento no teste convencional $(p<0,05)$. Utilizando $\mu \mathrm{CT}$, os cimentos apresentaram PCC, PCL e escoamento linear semelhantes $(p>0,05)$. Em conclusão, NMTAP e AHP apresentaram capacidade de preenchimento semelhante em canais mesiais curvos de molares inferiores sem presença de istmo. Embora o AHP tenha apresentado melhor escoamento que o NMTAP usando a metodologia ISO, não houve diferença entre esses materiais em relação ao preenchimento volumétrico quando avaliados por $\mu \mathrm{CT}$.

\section{Acknowledgements}

The authors thank Renato Luiz Carvalho for his assistance with the illustrations. The study was supported by the Coordenação de Aperfeiçoamento de Pessoal de Nivel Superior - Brasil (CAPES) - Finance Code 001 and FAPESP (2016/00321-0, 2017/19049-0, and 2018/19665-6).

\section{References}

1. Rossetto DB, Fernandes $S L$, Cavenago BC, Duarte MA, Ordinola-Zapata $R$, de Andrade FB. Influence of the method in root canal filling using active lateral compaction techniques. Braz Dent J 2014;25:295-301.

2. Schafer $E$, Nelius $B, B$ Burklein $S$. A comparative evaluation of gutta-percha filled areas in curved root canals obturated with different techniques. Clin Oral Investig 2012;16:225-230.

3. Keles A, Alcin H, Kamalak A, Versiani MA. Micro-CT evaluation of root filling quality in oval-shaped canals. Int Endod J 2014;47:1177-1184.

4. Jain $H$, Ballal NV. Comparison between the use of thermoplasticized gutta-percha and a polydimethyl siloxane-based material in filling internal resorptive cavities using spiral computed tomography. Microsc Res Tech 2019;82:149-152.

5. Qu W, Bai W, Liang YH, Gao XJ. Influence of warm vertical compaction technique on physical properties of root canal sealers. J Endod
2016:42:1829-1833

6. Tanomaru-Filho $\mathrm{M}$, Cristine Prado $\mathrm{M}$, Torres FFE, Viapiana $\mathrm{R}$, Pivoto-Joao $M M B$, Guerreiro-Tanomaru JM. Physicochemical properties and bioactive potential of a new epoxy resin-based root canal sealer. Braz Dent J 2019;30:563-568.

7. Tanomaru-Filho M, Andrade AS, Rodrigues EM, Viola KS, Faria G, Camilleri J, et al. Biocompatibility and mineralized nodule formation of Neo MTA Plus and an experimental tricalcium silicate cement containing tantalum oxide. Int Endod J 2017;50:e31-e39.

8. McMichael GE, Primus CM, Opperman LA. Dentinal tubule penetration of tricalcium silicate sealers. J Endod 2016;42:632-636.

9. Wu MK, Fan B, Wesselink PR. Leakage along apical root fillings in curved root canals. Part I: effects of apical transportation on seal of root fillings. J Endod 2000;26:210-216.

10. Kierklo A, Tabor Z, Pawinska M, Jaworska M. A microcomputed tomographybased comparison of root canal filling quality following different instrumentation and obturation techniques. Med Princ Pract 2015;24:84-91.

11. Oh S, Perinpanayagam H, Kum DJW, Lim SM, Yoo YJ, Chang SW, et al. Evaluation of three obturation techniques in the apical third of mandibular first molar mesial root canals using micro-computed tomography. J Dent Sci 2016;11:95-102.

12. Iglecias EF, Freire LG, de Miranda Candeiro GT, Dos Santos M, Antoniazzi

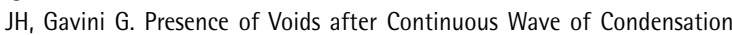
and Single-cone Obturation in Mandibular Molars: A Micro-computed Tomography Analysis. J Endod 2017;43:638-642.

13. Siqueira JF Jr, Favieri A, Gahyva SM, Moraes SR, Lima KC, Lopes HP. Antimicrobial activity and flow rate of newer and established root canal sealers. J Endod 2000;26:274-277.

14. Tanomaru-Filho M, Torres FFE, Bosso-Martelo R, Chavez-Andrade GM, Bonetti-Filho I, Guerreiro-Tanomaru JM. A novel model for evaluating the flow of endodontic materials using micro-computed tomography. J Endod 2017;43:796-800.

15. Vertucci FJ. Root canal anatomy of the human permanent teeth. Oral Surg Oral Med Oral Pathol 1984;58:589-599.

16. Schneider SW. A comparison of canal preparations in straight and curved root canals. Oral Surg Oral Med Oral Pathol 1971;32:271-275.

17. Gurgel-Filho ED, Feitosa JP, Gomes BP, Ferraz CC, Souza-Filho FJ, Teixeira FB. Assessment of different gutta-percha brands during the filling of simulated lateral canals. Int Endod J 2006;39:113-118.

18. Gurgel-Filho ED SE, Gomes BPFA, Ferraz CCR, Paula RCM, Coutinho-Filho TS, Souza-Filho FJ. Correlation between chemical composition and sealing ability of various gutta-percha brands using different filling techniques. Rev Port Estomatol Med Dent Cir Maxilofac 2012;53:153-158.

19. Collado-Gonzalez M, Tomas-Catala CJ, Onate-Sanchez RE, Moraleda JM, Rodriguez-Lozano FJ. Cytotoxicity of GuttaFlow Bioseal, GuttaFlow2, MTA Fillapex, and AH Plus on Human Periodontal Ligament Stem Cells. J Endod 2017;43:816-822.

20. Atmeh AR, AIShwaimi E. The effect of heating time and temperature on epoxy resin and calcium silicate-based endodontic sealers. J Endod 2017:43:2112-2118.

21. Donnermeyer D, Urban K, Burklein S, Schafer E. Physico-chemical investigation of endodontic sealers exposed to simulated intracanal heat application: epoxy resins and zinc oxide-eugenols. Int Endod J 2020;53:690697.

22. Atmeh AR, Hadis $M$, Camilleri J. Real-time chemical analysis of root filling materials with heating: guidelines for safe temperature levels. Int Endod J 2020;53:698-708.

23. Heran J, Khalid S, Albaaj F, Tomson PL, Camilleri J. The single cone obturation technique with a modified warm filler. J Dent 2019;89:103181.

24. Araujo VL, Souza-Gabriel AE, Cruz Filho AM, Pecora JD, Silva RG. Volume of sealer in the apical region of teeth filled by different techniques: a micro-CT analysis. Braz Oral Res 2016;30.

25. Torres FFE, Zordan-Bronzel CL, Guerreiro-Tanomaru JM, Chavez-Andrade $\mathrm{GM}$, Pinto JC, Tanomaru-Filho M. Effect of immersion in distilled water or phosphate-buffered saline on the solubility, volumetric change and presence of voids within new calcium silicate-based root canal sealers. Int Endod J 2020;53:385-391. 